\title{
Third West African Languages Congress
}

THe Third West African Languages Congress was held at Fourah Bay College, Freetown, from 26 to 31 March, under the auspices of the West African Languages Survey. Over 70 participants came from 17 countries, including II West African countries. A special grant from UNESCO enabled various people to come from more distant areas. Many of these had attended the previous Congresses, at Dakar and Accra, and their presence at Freetown was important for the continuity of linguistic work as a whole in West Africa.

More than twenty-five papers were read and many of these are to be published in the Journal of African Languages, edited by Professor Jack Berry. There was a special session on the teaching of English and French in West Africa, which was organized by Professor Dykstra of Columbia University Teachers' College. Another similar session is planned for next year's Congress, and it is hoped that some kind of West African modern languages teachers' association may develop from it.

The Congress was entertained at a sherry party given by Fourah Bay College and officially opened by the Governor-General, Sir Henry Lightfoot-Boston, who then inspected the special exhibit of linguistic works published at Freetown during the nineteenth century, which Dr. Paul Hair had set up in the college library. Later in the week Sir Henry and Lady Lightfoot-Boston gave a sherry party for the participants at Government House, Freetown. Professor Greenberg, the chairman, gave a public lecture one evening at the British Council on 'The History of Linguistic Work in West Africa'.

This year marks the end of the first phase of the West African Languages Survey. There are two Survey Fellows still in the field, Dr. David Crabb, near Ikom, in Eastern Nigeria, and Dr. Marcel Bôt at ba-Njock, near Yaoundé, Republic of Cameroon. Professor Robert Armstrong, the Field Director, has resigned and has accepted the post of Research Professor of Linguistics, Institute of African Studies, University of Ibadan. It was announced that the Ford Foundation has made a grant of $\$ 75,000$ to extend the life of the Survey for another three years, on a somewhat different basis. There are to be three more annual congresses. Substantial scholarship aid will be available, on the basis of matching grants, to Africans who wish to do field studies for advanced degrees in linguistics. The programme of grantsin-aid of research is to be continued and will be administered jointly by Professor Joseph Greenberg, now of Stanford University, California, and M. Maurice Houis, of IFAN, University of Dakar, to whom requests should be addressed. Much of the material resulting from the work of the Survey is to be published in a series of monographs which will be issued by the Cambridge University Press to accompany the new Journal of West African Languages (see p. 367).

The Fourth West African Languages Congress will be held at the University of Ibadan, I6-24 March 1964. It is hoped that it may consider the establishment of a permanent West African Linguistic Society.

\section{(Communicated by Professor R. G. Armstrong)}

\section{American Summer Institute in African Languages and Area Studies}

Following the successful pilot institute in African Languages and Area Studies held at Michigan State University last summer, the Department of Health, Education and Welfare this year granted from its National Defense Education Act budget funds and a number of tuition scholarships to hold a second special summer programme. This was held from June to August under the direction of the African Studies Center of the University of California Los Angeles (Director: Dr. James S. Coleman). 